\title{
A Qualitative Exploration of Effective Creative / Convergence Type of Class in Middle and High School Physical Education Classes
}

\author{
https://doi.org/10.3991/ijoe.v16i15.18721 \\ Seung-Yong Kim \\ Kyonggi University, Suwon, South Korea \\ dragonkimakyonggi.ac.kr
}

\begin{abstract}
The purpose of this research was to examine the courses and experiences of middle and high school physical education teachers based on their field experience, suggestions, and school educational environment and to explore in-depth to reflect learner-centered creative/ convergence type of education in physical education classes. To achieve the purpose of the research, four physical education teachers were selected as research participants, and after conducting in-depth interviews, inductive category analysis procedures among qualitative research methods were used to derive the meaning analysis and results of the data For learner-centered creative/convergence type of classes, first, individual competencies of field teachers will have to be developed first. Second, there will have to be a solution to the problem of conflict of interest between teachers and teachers. Third, there should be case education, organizing, systematizing, and refined models for creative/convergence type of education. Fourth, there should be a realistic and direct approach and support, not an expression as an abstract language. The goals of the physical education subject matter include important parts that represent the direction that physical education should pursue and the learning reach that learners should achieve. Therefore, if education content is presented to solve problems more specifically and creatively, more suitable results will be produced for fostering creative/convergence type of talent.
\end{abstract}

Keywords - Creative, convergence, creative/convergence type of class, physical education, PE classes

\section{Introduction}

Human resources are more important than any other resource in a dynamic and rapidly changing modern society. A very important element of this core resource is knowledge. Therefore, knowledge in modern society can be said to be alive and moving, and this knowledge goes through a process of rapidly disappearing and generating in line with the times, and its validity period becomes shorter and shorter. In this regard, Chichilnisky [1] called the changes in knowledge that lead to changes in the social and economic system 'knowledge revolution'. 
In particular, in a knowledge-based society, the elasticity and flexibility of knowledge are not a process of following or imitating the existing regularized knowledge, but rather a process of creativity, activity, and activeness, which can be expected to create new knowledge and further require learning to expand knowledge. Thus, the approach of learning administered in the process of creating knowledge, namely the amount and quality, determines the value of that knowledge. As such, the form of knowledge creation and learning will soon require significant changes in school education.

In general, today's school education has adopted and operated a reproduction (copy)oriented form of education. However, this type of education does not reflect the changing nature of knowledge. Because the cycle of knowledge change is getting very short in the modern educational environment. In other words, the transition and adoption of education methods that can lead to change, as well as the prediction of the direction in which education today, can lay the foundation for gaining an absolute advantage in the rapidly changing social environment. Therefore, it is essential to have a form of production (creation) - oriented, namely the cultivation of creativity and corresponding competencies, and an educational environment that enables the learning of convergent knowledge, according to the trends and needs of the times.

On the other hand, physical education and sports activities contribute greatly to improving health and fitness. In particular, it provides students with strong physical strength and healthy bodies that can last long for study. If students are not grounded in this area, they lose concentration and attention and their learning efficiency $[2,3]$. In addition, school PE provide a foundation for lifelong sports as well as a healthy body and a healthy life [4]. In that sense, physical education is an essential element in forming a healthy body, spirit, and body [5].

Middle and high schools will have a broad understanding of the history, characteristics, and types of games of various sports, learn the functions, principles, and methods necessary for sports activities, use them in real games, as well as learn creative game strategies. In this process, students are trained to learn problem-solving skills or desirable ways of interpersonal relationships so that they can successfully perform the competition [6]. In addition to context, during physical education classes in middle and high schools, teachers will organize various teaching methods and contents to help students understand the definition of sports and the value of sports.

This is also highlighted in recent studies $[7,8]$ in the importance of the constructivist teaching and learning process for the development of future sports education content and educational innovation. Constructivism means that learners form and organize knowledge on their own, meaning that students in constructivism interact with individuals and situations in acquiring and refining knowledge. Thus, learners in constructivism can acquire meaningful knowledge, expect higher mental capacity, and promote creativity and self-directed learning skills $[9,10]$. This is linked to a learner-centered [11] teaching strategy.

However, for physical education teachers at the site, learner-oriented physical education classes are always a subject of concern, and it is the concern and reality of school sites that they still have to solve many challenges. In particular, the educational implications of one teacher, who recognizes diversity in students and is oriented toward a 
learner-centered class, may vary in number and the results may also be difficult to predict [12]. Therefore, studies that help revitalize physical education classes with learners are drawing keen attention, and there are growing calls for the application of various cases of newly developed physical education classes with educational intent to be applied to school sites [13].

In addition, in the process of changing physical education from teacher-centered to learner-centered classes, not only the professor's perception of value but also the learner's perception of value is very important. This is because students' perception of value in class helps them to have a clear understanding of what they learn from the class [14].

In the face of the Fourth Industrial Revolution, we have swollen expectations and vague fears that we do not know. Then we should check what preparations our education is making in line with the rapidly changing era of the Fourth Industrial Revolution. Perhaps it is no exaggeration to say that the change in education, as mentioned above, will soon lead to changes in our society and the future. In this regard, the purpose of this study is to present the direction of future school education through the qualitative exploration of creative / convergence type of classes in relation to how future school education should change and what type of direction it should take.

Therefore, the purpose of this research is to examine the courses and experiences of middle and high school physical education teachers based on their field experiences and suggestions, and the school educational environment, and to explore in-depth so that learners-oriented creative / convergence type of education can be reflected in physical education classes. Through this, we want to provide basic data and implications for the revitalization of learner-oriented physical education classes that pursue diversity.

\section{Research Methods}

\subsection{Research participants}

The research participants were four physical education teachers working in middle and high schools. The method of selection of participants was chosen from purposeful sampling methods among the non-probabilistic. The characteristics of the study participants were as shown in Table 1.

Table 1. Characteristic of research participants

\begin{tabular}{|c|c|c|c|}
\hline & Age / Gender & Teaching career & Affiliation \\
\hline A & 48/ Male & 18 years & High school \\
\hline B & 39/ Male & 10 years & High school \\
\hline C & $46 /$ Female & 20 years & Middle school \\
\hline D & 38/ Male & 5 years & Middle school \\
\hline
\end{tabular}




\subsection{Methods and procedures for data collection}

This research was conducted through in-depth interviews and collection of related data from September 2019 to June 2020. In particular, in-depth interviews with four physical education teachers and related document data were important data collection methods, and they served as important factors that could affect the results of the study. Interviews conducted in-depth interviews using unstructured and semi-structured interview methods to obtain more in-depth information on the qualitative exploration of learner-centered creative / convergence type of classes and the activation of physical education classes. In order to identify information not obtained from in-depth interviews, various types of documents were obtained through the formal or informal gathering of relevant data and used as evidence for deriving research results. Securing information through these interviews and documents was collected and organized through a circular process.

In-depth interviews were conducted through individual interviews in the past and present extensions based on information provided by creative / convergence type of physical education classes, indirect experiences through fellow teachers, and research classes conducted by physical education teachers themselves. The main contents of the interview were as follows: First, creative teaching methods that can be applied in the site of physical education, second, integrated teaching methods within and between subjects matter in the site of physical education, and third, problems and difficulties in the operation (application) of creative/convergence type of classes, fourth, solution plan and improvement opinions were examined separately.

\subsection{Data analysis method}

In order to achieve the purpose of the research, inductive category analysis procedure [15] of the qualitative research data analysis methods were used, and the results were finally derived and interpreted accordingly by organizing, systematizing, and categorizing the collected data [16]. The results obtained through such an analysis process were reinterpreted in the context of qualitative exploration related to the purpose of the research and described individually or comprehensively to ensure internal validity through the veracity of the data.

\subsection{Research's veracity}

The criteria for validity and reliability in qualitative studies can be explained by the veracity and certainty of the data [17]. Therefore, in order to enhance the veracity of the data in the process of collecting and analyzing the data and to obtain certainty, the research efforts were made to secure the veracity of the research by utilizing techniques such as triangular verification methods, consultation among colleagues, in-depth technology, and review among members. 


\section{$3 \quad$ Results and Discussions}

\subsection{Creativity classes}

In order for creative classes to proceed efficiently and effectively, learning at the understanding level is first important. In other words, because prior learning is required, the use of 'flipped learning' or 'electronic textbooks' is needed. This is because it is difficult to expect diverse and productive creative teaching activities unless the level of understanding of basic knowledge is preceded within limited class time. However, it is not realistic for physical education teachers at individual schools to develop content related to prior learning. Therefore, it is believed that if the education office provides administrative and financial support while exercising collective competence in teachers and subject matter research groups actively working in each region, it will develop tools related to prior learning that are easier and more advanced.

"There is a limit to the traditional way of physical education. So, after learning the steps of knowledge or understanding through 'flipped learning' and etc., I think it is possible to apply deep classes in the classroom or in the playground. I think these courses serve as an important bridgehead for maximizing efficiency and expanding class diversity and creativity as part of the basic course to creative classes." (Teacher C)

And the accumulation of theoretical and empirical studies related to subject matter creativity is necessary. In addition, the development of subject matter creativity and personality measurement tools that can be measured on creativity or personality should be made for use in school sports sites. These measurement tools will also help the academic development of physical education. And physical education teachers at the site should be able to apply and utilize it easily. Because research on creativity in the field of physical education requires the development of measurement tools to lay the theoretical foundation.

"This type of class right now... I'm not sure if it's suitable for creativity classes, whether it's doing it right or not, and I'm not sure if it's going wrong. I think it's important that we can distinguish what criteria, steps, levels, etc., and that we can use that distinction to provide the least amount of information about how to prepare and plan." (Teacher A)

Meanwhile, through the creative classes, physical education teachers perceived the importance of physical education classes in the curriculum as increasing and expanding the scope. These results mean that meaningful learning takes place in a creative/convergence type of physical education classes in physical education classes, as well as enabling a variety of valuable educational experiences.

"I think creative classes can be run in many different ways in physical education classes. And since it is possible whole-person educated curriculum than any other subject matter, I think the scope of the creative-based class operation is very wide and its effects can be broadened and expanded compared to other subjects." (Teacher B) 
And it was confirmed that the role and necessity of physical education are increasing in order to resolve health and lifelong sports, education of sensibility and character, and conflicts among classes in a multicultural society. Therefore, physical education classes have a positive impact on not only function and health, but also other important qualities, confirming the possibility that physical education subjects can be more complete than other subject matter. This can be said to indicate that the emphasis on the role and importance of physical education can contribute to the expansion of the field of physical education.

\subsection{Convergence classes}

Integration within the subject matter: Various convergence education needs to be attempted not only in other subjects but also in physical education classes. Because convergence education is now becoming a necessity in fostering creative talent. But convergence education has yet to be tried well due to the lack of preparation of school teachers. However, physical education can be integrated into various subjects such as sports psychology, sports biomechanics, sports sociology, and physical education measurement evaluation. Therefore, it is necessary to form various conditions so that teachers in the field can try to integrate into the subject matter through various training programs as well as institutional support for convergence within the subject matter.

"Physical education is better for convergence than other subjects' matter. Basically, it is possible to connect with various basic studies through integration within the subject matter. Furthermore, I think it has very high efficiency in Integration between subject matter." (Teacher A)

In addition, it is important to set up conditions for teachers to display their skills between "classes that require thorough preparation" and "teacher's heavy workload." In particular, thorough preparation is needed for the position of teachers who offer new classes, such as in-text convergence forms, during the creative/convergence type of classes. Of course, it is natural for any teacher to prepare hard for his or her classes. But we cannot rely solely on this titular cry to persuade teachers to practice good lessons.

"It takes a lot of preparation. It's easy to approach. Just mix it up? It's easy to think you can do it. Of course, it takes thorough preparation to see the convergence of the results. But in reality, it is not easy to study teaching materials. Because there is a lot of workloads given to teachers other than student guidance and preparation for classes. If you ignore this or try to fit it in somehow without considering a realistic teaching environment... It's hard to be positive for most of the time." (Teacher D)

The results of SWOT analysis to practice STEAM education in school sites point out that teachers are overloaded with work due to weaknesses. After all, it is imperative to improve the system to ensure that competent teachers do not spend time on administrative tasks unrelated to class preparation so that they can practice quality education. If you are still losing a lot of time to things that are not directly related to teaching, it would be impossible to nurture students with creativity and a good personality through quality education. 
Integration between subject matter: Teachers presented the following experiences and opinions on convergent classes in the Integration between subject matter centered on physical education. First of all, since convergence classes include various subjects in the course of implementation, understanding sufficient convergence education should precede anything else in the course of preparing for classes. Since then, it has been suggested that it is important to carefully analyze textbooks in each subject to extract tasks that can be convergence education and thoroughly design class plans for each class time.

"First of all, it should include the basic subject matter content that each subject matter should contain. The understanding of each subject matter between teachers should precede it. And I think that the fundamental concerns about actual activities and social development should be raised. In particular, since physical education is a subject that accompanies physical activity knowledge, there should be sufficient understanding and application of the understanding of the teaching and interaction with other subjects." (Teacher C)

When convergent classes were proceeded, at first preparation was hard and proceeding classes had many problems but as classes continued teachers adapted. Although it was difficult as many subjects spent a lot of time and effort to find meaning in one class, it became a meaningful experience to discover the possibility of convergence education in the reactions of students. It is also expected that this process will continue to apply and develop convergence education.

Not only teachers but also students who experienced convergence classes said that they had difficulty or did not know well at first because of unfamiliarity. However, as the class progresses, it turns out that people are interested in new ways of education and have fun. Through convergence education, it was confirmed that students had various experiences and learned through the convergence of different subjects, resulting in more diverse thoughts and thoughts.

"Convergence classes are easy to say but very difficult to proceed. It's not just about integrating this and that's all. Worries and efforts in the preparation process are natural, and trial and error should be prepared to some extent. But as those efforts gradually bear fruit... I think there are a lot of positive and positive factors in convergence classes. Many students are confused at first. Huh? What's this? Haha... and then you get used to it, and then you find out through the class that there are many cases where you discover the meaning of the convergence class without knowing." (Teacher B)

Students naturally understood scientific concepts through physical activities in physical education, produced creative tools using various ideas, and expanded their thinking with friends by applying them to modified game classes. Conflict with friends through discussion and debate activities was recognized as a process and it was confirmed that discussion activities actively resolved them. This gave students themselves a chance to motivate their classes.

"Diversity. You find a lot of unexpected results. And it's not the end, it's the constant spread. The basic skills that we needed as members of society, such as cooperative spirit, and the cultivation of attitudes toward interpersonal relationships and interactions, were found through convergence classes." (Teacher A) 
Through the process of mutual respect and cooperation, students participated in the class harder and developed core competencies through convergence education such as communicating with each other. This was an important factor to ensure that integrated classes centered on physical education could be applied to the field and that the application in various fields could bring about the results of continuous growth and development.

"Because there is no institutional mechanism to provide feedback or motivation for convergence results, and because the results of convergence classes cannot be immediately seen, policy organizing, refined forms, and cases are required." (Teacher D)

On the other hand, it was found that teachers were basically quite burdened with trying to integrate some subjects. And it turns out that physical education can be linked to many subjects such as art, music, science, and math. However, the difficulty of convergence classes in inter-disciplinary integration could be found to be inherently inherent, as the enthusiasm among teachers must be accompanied. Therefore, it is judged that institutional mechanisms should be in place to provide feedback or motivation for convergence results, and that policy organization, systematic manuals, and assessments, and the presentation of reference points are required.

\subsection{Creativity / convergence type of classes}

Physical education teachers are found to recognize the value of career exploration through the contents and methods of the integrated sports class in relation to the free semester system as a sports class that creates value through convergence. The results of these studies can be interpreted that it is desirable for career education related to physical education to be conducted as a convergence education through a free semesterbased sports-focused model.

It can also be seen that students can choose their future sports career path and expand their career exploration. Therefore, it can be interpreted that the convergence-oriented career education provides the opportunity to experience various vocational groups directly or indirectly in school education and that it is very efficient to develop practical skills in the performance of the role of vocational groups. In addition, it is believed that the value of career exploration can be realized in the free-semester class through convergence because students' career proficiency can be enhanced through the free-semester class.

It has been confirmed that the physical activity knowledge and value of physical education classes of physical education classes are combined with other academic fields to create new values and cultures by cultivating creative problem-solving skills and desirable personality in various situations. Therefore, teachers recognize that convergence classes need more time and effort than conventional classes, but they should continue to increase in the future. However, physical education teachers rarely learn how to design convergence sports classes or receive convergence sports programs, and although the demand for convergence education is large, convergence classes at the actual school site are limited by human resources and physical limitations. Therefore, the 2015 revised curriculum document for fostering creative/converged talents needs to precede 
the understanding of physical education teachers preparing for classes on convergence education in order to set the direction of practice for the success of convergence education with physical education, and human and physical support is required for teachers to continue to study and conduct convergence classes.

In addition, it has been widely shared among physical education teachers that the legitimacy and necessity of convergence education have already been established in the Korean educational society and that convergence sports classes are very useful to learners in an educational way, but the academic discourse on convergence classes in the field of school sports has rarely existed. Therefore, it is necessary to show the unique value of convergence classes and to provide various academic grounds for institutional support. Meanwhile, it is pointed out that convergence education is difficult to indicate convergence thinking due to the strict separation of subjects in secondary education courses, and that cooperative classes among teachers can lead to conflicts among teachers. Therefore, based on the results of this study, teachers, subject research groups, and teachers' learning communities are considered important factors to support the development of teachers' expertise in convergence classes.

\section{Conclusion and Suggestions}

Looking at the document system of the 2015 revised physical education and curriculum to foster creative/convergent human resources required by the future society, the nature, content system and achievement standards of the physical education curriculum, teaching and learning methods, and evaluation items all emphasize the convergence ability to acquire physical activities and to comprehensively acquire the values pursued by physical activities. And it can be said that it is composed of appropriate content in that it emphasizes the ability to solve problems creatively in the process of performing physical activities and is organized to care for others based on the right personality. In addition, the 'goal' of the document system of the physical education subject matter aims to achieve and experience the abilities necessary for a lively and healthy life through physical activities and to learn all the functions, knowledge, and attitudes of physical activities by converging the values of health, challenge, competition, expression and safety of physical education classes, and to live with a sense of responsibility in one's life as a desirable society. However, it is not clearly presented to develop the ability to solve problems creatively, which is a key element of fostering creative/converged talent that physical education textbooks are aiming for, and thus needs to be improved to suitable content.

I think the goal of the physical education subject matter will be more suitable for fostering creative/converged talents if the content is presented to solve the problem more clearly and creatively, as it contains important parts that indicate the direction the physical education curriculum should pursue and the learning reach that the learner should achieve. In conclusion, for learner-centered creative/converged classes, the development of individual competencies for field teachers will first have to be followed. Second, there will have to be a solution to the problem of conflicts of interest among teachers. Third, there should be case education, organizing, and refined models for 
creative/convergence education. Fourth, there will have to be a realistic approach and support, not an expression as an abstract word.

On the other hand, the subjectivity perception of creative/converged physical education classes were explored only by teachers at school sites, so it is necessary to look at what subjective values, attitudes, and perceptions creative/converged physical education classes come to for students who are actually subject to creative/converged classes at school. It is also suggested that objective research on the operation of classes using qualitative and quantitative research and prior and post-examples should be carried out in follow-up studies as this study deals with subjectivity of creative/converged physical education classes.

\section{$5 \quad$ References}

[1] Chichilnisky, G. (1998). The knowledge revolution. The Journal of International Trade \& Economic Development, 7(1), 39-54. Retrieved from: https://mpra.ub.unimuenchen.de/8891/1/MPRA_paper_8891.pdf

[2] Baeten, M., Kyndta, E., Struyvena, K., \& Dochya, F. (2010). Using student-centered learning environments to stimulate deep approaches to learning: factors encouraging or discouraging their effectiveness. Educational Research Review, 5(3), 243-260. https://doi.org/10.1016/j.edurev.2010.06.001

[3] Weiss, M. R. (2004). Development sport and exercise psychology: A lifespan perspective (pp. 1-26). Morgantown, WV: Fitness Information Technology. Retrieved from: https://psycnet.apa.org/record/2004-18908-001

[4] Li, J., \& kim, S. Y. (2019). On the Development Direction and Policy of Chinese School Physical Education under the Background of 'Healthy China 2030 Program'. International Journal of Emerging Multidisciplinary Research, 3(1), 21-27. https://doi.org/10.22662/ IJEMR.2019.3.1.021

[5] Bailey, R., Armour, K., Kirk, D., Jess, M., Pickup, I., \& Sanford, R. (2009). The educational benefits claimed for physical education and school sport; An academic review. Research Papers in Education, 24(1), 1-27. https://doi.org/10.1080/0267152070 $\underline{1809817}$

[6] Ministry of Education. (2015). Physical education curriculum. Ministry of Education Notice No. 2015-74 [Attachment 11]. Sejong: Ministry of Education Publishing. Retrieved from:https://www.moe.go.kr/boardCnts/view.do? boardID=141\&lev=0\&statusYN=C\&s=moe \&m=0404\&opType=N\&boardSeq=60747

[7] Devecioglu, S., Sahan, M., Tekin, M., \& Yildiz, M. (2012). Development of Innovation Strategies for Sports Education. Procedia - Social and Behavioral Sciences, 46, 445-449. https://doi.org/10.1016/j.sbspro.2012.05.139

[8] Jorge, K., Ramón, S., \& Ruth, J. (2019). Thinking Skills and Creativity, in press, accepted manuscript, Available online 30 March 2019. Retrieved from: https://www.journals.elsevier.com/thinking-skills-and-creativity 1871-1871(19)30255-x

https://doi.org/10.1016/s

[9] Savery, J. R., \& Duffy, T. M. (1995). Problem based learning: An instructional model and its constructivist framework. Educational Technology, 35(5), 31-38. Retrieved from: https://www.jstor.org/stable/44428296

[10] Spiro, R., Feltovich, M. J., \& Jacobson, M. J. (1991). Cognitive Flexibility, constructivism, and hypertext: Random access instruction for advanced knowledge acquisition in ill- 
structured domain. Educational Technology, 31(5), 24-33. Retrieved from: https://www.jstor.org/stable/44427517

[11] Paris, C., \& Combs, B. (2006). Lived meanings: what teachers mean when they say they are learner-centered. Teachers and Teaching, 12(5), 571-592. https://doi.org/10.1080/ 13540600600832296

[12] Bailey, R. (2006). Physical education and sport in school: A review of benefits and outcomes. Journal of School Health, 76(8), 397-401. https://doi.org/10.1111/j.17461561.2006.00132.x

[13] Weiss, M. R. (2011). Teach the children well: A holistic approach to developing psychosocial and behavioral competencies through physical education. Quest, 63(1), 55-65. https://doi.org/10.1080/00336297.2011.10483663

[14] Bendell, A., Solomon, D., \& Carter, J. M. (1995). Evaluating project completion times when activity times are erlang distributed. Journal of the Operational Research Society, 46(7), 867882. https://doi.org/10.1057/jors.1995.118

[15] M. Q. Patton. (1990). Qualitative evaluations and research methods (2nd edition). Newbury Park (California): Sage Publications. Retrieved from: https://psycnet.apa.org/record/ 1990-97369-000

[16] R. C. Bogdan \& S. K. Biklen. (1982). Qualitative research for education: An introduction to theory and methods (Third edition). Boston: Allyn and Bacon, Inc. Retrieved from: https://go.gale.com/ps/anony-

mous?id=GALE\%7CA179076948\&sid=googleScholar\&v=2.1\&it=r\&linkaccess=abs\&issn $=14480980 \& \mathrm{p}=\mathrm{AONE} \& \mathrm{sW}=\mathrm{W}$

[17] Lincoln, Y., \& Guba, E. (1985). Naturalistic inquiry. CA: Sage.

\section{Author}

Seung-Yong Kim is a professor of major in physical education at the Graduate School of Education at Kyonggi University in Korea. His areas of interest are teachinglearning factors, and he is researching teacher training and sports pedagogy. Email: dragonkim@kyonggi.ac.kr

Article submitted 2020-09-21. Resubmitted 2020-10-25. Final acceptance 2020-10-28. Final version published as submitted by the authors. 